\title{
NOVASLETURAS DOMODERNISMO
}

\author{
Maria de Fátima Morethy Couto, Profa. Dra. \\ mfmcouto@iar.unicamp.br
}

Nas três últimas décadas, os escritos de Clement Greenberg vêm sendo objeto de análise da parte de diferentes críticos e historiadores em todo o mundo, dentre os quais destacam-se os nomes de Rosalind Krauss, Leo Steinberg, Hubert Damisch, Yve-Alain Bois e Thierry de Duve. Em 1993, um colóquio sobre o legado de Greenberg reuniu em Paris alguns dos maiores estudiosos de sua obra e demonstrou "que a era dos adeptos incondicionais e dos detratores obstinados cedeu lugar a um trabalho de recepção propriamente crítico". ${ }^{1} \mathrm{O}$ contínuo interesse suscitado pelos textos do crítico norte-americano comprova sua importância para o pensamento estético do século XX. Mas reconhecer tal valor não implica em abraçar por completo a teoria greenberguiana ou considerála como uma causa a ser defendida. Além disso, a crise do modernismo, como alertou Hans Belting, "também afetou a escrita da história da arte e a confiança em uma continuidade linear da arte", como proposta por Greenberg. ${ }^{2}$

Ao identificar como característica principal da arte moderna sua progressiva rejeição de todas as convenções históricas para lidar apenas com os constituintes específicos de cada meio e ao tentar inserir a produção de vanguarda na continuidade da grande tradição pictórica, Greenberg aderiu a uma concepção evolutiva e linear da história da arte. Na realidade, se a arte norteamericana dos anos 1950, em especial o expressionismo abstrato, parecia encaixar-se com perfeição na explicação por ele proposta, diferentes tendências artísticas que surgiram na década seguinte, como o minimalismo, a pop art ou ainda a arte conceitual promoveram o colapso dos paradigmas modernistas. Diante de sua dificuldade em aceitar o novo, Greenberg não hesitou em promover "excomunhões", rejeitando o trabalho de alguns artistas contemporâneos que, em sua opinião, buscavam apenas escandalizar e chocar o público.

Seu julgamento contra a pop art, por exemplo, foi bastante severo. Para Greenberg, a $p \circ p$ art era uma manifestação vanguardista e não verdadeiramente de vanguarda. Ela era apenas "uma escola e uma moda", equivalendo "a um novo episódio na história do gosto, mas não a um episódio autenticamente novo na evolução da arte contemporânea. (...) Por mais divertida que seja a pop art, não a considero realmente original", escreveu no mesmo ano em que Andy

\footnotetext{
${ }^{1}$ Jean-Pierre Criqui e Daniel Soutif (org.), Clement Greenberg. Les cahiers du Musée national d'art moderne, Paris, Centre Georges Pompidou, no 45/46,outono-inverno 1993.

${ }^{2}$ Hans Belting, Art History after Modernism, Chicago e Londres, The University of Chicago Press, 2003.
} 
Warhol apresentava suas Brillo Boxes em Nova York. ${ }^{3}$ Em entrevista concedida cinco anos mais tarde, ou seja, em 1969, Greenberg voltou ao ataque, afirmando que achava a arte $p o p$ pouco excitante porque "ela era muito familiar (...) como ilustração e ao mesmo tempo trivial em termos de pintura pura. (...) A arte $\not \circ p$ é muito agradável, muito facilmente amável; não desafia suficientemente o gosto. Por isso tornou-se popular tão rapidamente. E é também por isso que está se esgotando - ou que já se esgotou - mesmo aos olhos de seus devotos". Embora considerasse a arte minimalista mais instigante, ela ainda era, em sua opinião, "uma arte menor, agradável, e por isso também pegou tão rapidamente. Fosse ela uma arte grande, desafiadora, provocadora dos gostos não teria feito sucesso. Ela teria encontrado as mesmas (...) resistências que a arte maior quase sempre encontrou nos últimos 150 anos ou mais". ${ }^{4}$

Temendo uma fuga, um desaparecimento do gosto, que conduziria fatalmente à decadência, Greenberg criticava a arte conceitual por entendê-la como um ataque às mais altas ambições que deveriam reger a melhor arte em todos os tempos. Em sua opinião, a primeira investida frontal contra o 'formalismo' surgida no seio da vanguarda, ou do que era conhecido como tal, foi a de Duchamp e do dadá, e ela se firmou imediatamente como rebaixamento de aspirações", afirmou em $1972 .{ }^{5}$

Anos mais tarde, em debate promovido pela Universidade de Otawa em 1987, Greenberg reiteraria esse pensamento, declarando que a primazia da idéia na arte fora a maior responsável pela valorização de modismos e de vanguardismos na segunda metade do século XX. As idéias, segundo ele, haviam devastado a arte. "A arte como idéia é boa para aqueles que não esperam muito da arte, não exigem suficientemente, não buscam uma experiência estética verdadeira mas sim algo que podem classificar e identificar como novo, o novo do momento". 6

\footnotetext{
${ }^{3}$ Catálogo da exposição Post-painterly abstraction, organizada por Greenberg em 1964 no Los Angeles County Museum e da qual participaram trinta e um artistas.

4 "Entrevista com Lily Reino", in John O’Brian (org.), Clement Greenberg. The collected Essays and Criticism, Chicago, University of Chicago Press, 1986-1993, vol. 4, pp. 303-314.

${ }^{5}$ Clement Greenberg, "A necessidade do formalismo", in Glória Ferreira e Cecília Cotrim (orgs.), Clement Greenberg e o debate crítico, Rio de Janeiro, Ministério da Cultura/Funarte e Jorge Zahar Editor, 1997, p. 128. Publicado originalmente in New Literary History, vol. III, 1971-72. Como observa Yve-Alain Bois, "Duchamp será o inimigo maior de Greenberg" (....) porque ele havia considerado a convenção institucional, a que lida com o valor expositivo de toda obra de arte, como uma condição tão necessária quanto, ou talvez mais necessária do que a planaridade, para a existência da obra, e por este motivo igualmente digna de ser objeto de uma análise reflexiva Yve-Alain Bois, "Les amendements de Greenberg", in Les cahiers du Musée national d'art moderne, op. cit., p. 53.

${ }^{6}$ Entretanto, como observa Hans Belting, "a história da arte conceitual aparece de outra forma quando ela é compreendida não como uma simples corrente artística ou um episódio, mas como um sintoma de uma crise que não mais permitiu a arte materializar-se como trabalhos formais (ou exposições concretas) e não mais confirmaria a lógica institucional do mercado de arte e do museu". In Hans Belting, op. cit, p. 116.
} 
A rejeição de Greenberg da arte pop, minimalista ou ainda da arte conceitual está intimamente associada à sua concepção de arte moderna, cuja versão mais elaborada se dá em seu célebre artigo "Pintura modernista", publicado originalmente em 1960. Nele, o crítico norte-americano sintetiza seu pensamento sobre as características principais do modernismo, retomando questões que abordara em textos anteriores, em especial "Vanguarda e Kitsch" e "Rumo a um mais novo Laocoonte", publicados por volta dos anos 1940. Identificando como o fio condutor da evolução da "melhor arte nos últimos cento e poucos anos" a pesquisa "do que havia de único e irredutível não somente na arte em geral, mas também em cada arte em particular", Greenberg afirma então que "a essência do modernismo reside no uso de métodos de uma disciplina para criticar essa mesma disciplina, não no intuito de subervertê-la, mas para entrincheirá-la mais firmemente em sua área de competência”. ${ }^{X X X X}$ Em sua opinião, "O modernismo, seguindo essa direção, tornou a pintura mais consciente de si mesma. (...) A tarefa da autocrítica passou a ser a de eliminar dos efeitos es-pecíficos de cada arte todo e qualquer efeito que se pudesse imaginar ter sido tomado dos meios de qualquer outra arte ou obtido através deles. Assim, cada arte se tornaria "pura", e nessa "pureza" iria encontrar a garantia de seus padrões de qualidade, bem como de sua independência". ${ }^{8}$

Outro tópico central de "Pintura modernista" diz respeito à relação entre a arte moderna e a grande tradição pictórica do passado. Segundo Greenberg, enganavam-se aqueles que acreditavam que o modernismo fosse "o início de uma era inteiramente nova na arte" pois ela significava a "continuidade inteligível do gosto e da tradição". "Não é supérfluo insistir", escreve ele, "que o modernismo jamais pretendeu, e não pretende hoje, nada de semelhante a uma ruptura com o passado. Pode significar uma transição, uma separação da tradição, mas significa também o prolongamento de sua evolução. A arte modernista estabelece uma continuidade com o passado sem hiato ou ruptura, e seja qual for seu término, nunca deixará de ser inteligível em termos de continuidade da arte". ${ }^{9}$

Apesar de todas as transformações ocorridas no cenário artístico norteamericano, Greenberg continuaria a defender essa idéia em 1972, afirmando que, "em geral, [a resposta modernista] permanece apenas ostensivamente como ruptura e como radical. $\mathrm{Na}$ verdade, trata-se de um movimento dialético que opera no sentido de manter ou restaurar a continuidade: uma continuidade

\footnotetext{
${ }^{7}$ Clement Greenberg, "Pintura modernista", in Glória Ferreira e Cecília Cotrim (orgs.), op. cit., pp. 101-110. Para a versão original, ver John O’Brian (org.), op. cit., vol. 4, pp. 85-93.

${ }^{8}$ Cabe porém ressaltar, como o fez, por exemplo, Yve-Alain Bois, que Greenberg considerava tal planaridade mais como um ideal almejado do que como uma meta possível de ser alcançada.

${ }^{9}$ Clement Greenberg, "Pintura modernista", in Glória Ferreira e Cecília Cotrim (orgs.), op. cit., pp. 101-110.
} 
absolutamente essencial; continuidade com os padrões estéticos mais elevados do passado. Não são estilos, maneiras ou modos passados particulares que devem ser mantidos ou restaurados, mas padrões, níveis de qualidade. E esses níveis devem ser preservados do mesmo modo como foram alcançados primeiramente: por renovação e inovação constantes". 10

Cabe ressaltar que a crítica greenberguiana é pautada pela idéia de gosto, pela crença na existência de critérios de julgamento que podem ser compartilhados por um número significativo de pessoas e pela certeza de que um profissional sensível é capaz de distinguir a boa arte - aquela mais adequada a seu tempo - da simples imitação ou da novidade sem conteúdo. Se os valores estéticos não são eternos, eles são porém transmissíveis e não mudam radicalmente de geração à geração. "Seja na arte ou em qualquer campo", declarou Greenberg em 1940, "todos os valores são valores humanos, valores relativos. Parece ter subsistido, contudo, através dos tempos, uma espécie de acordo geral entre a humanidade culta no tocante ao que fosse arte de boa ou de má qualidade. O gosto variou, mas não além de certos limites. (...) Podemos ter pássado a preferir Giotto a Rafael, mas ainda reconhecemos que Rafael foi um dos melhores pintores de seu tempo". Compreende-se, portanto, que o trabalho de Duchamp seja inaceitável para Greenberg, pois nele a noção de "boa arte", regida pelo gosto, é voluntariamente descartada. A estética de Greenberg, ao contrário, "permanece fundamentalmente uma estética de connoisseurship: trata-se de ter olho e gosto, e o bom gosto é um juiz intemporal perante o qual as obras comparecem, à espera de julgamento". ${ }^{11}$

Seguindo a trilha aberta por Greenberg, também Michael Fried, durante a década de 1960, defendia a validade dos paradigmas modernistas para a análise dos movimentos mais atuais, reafirmando que os conceitos de qualidade e valor eram centrais para a arte e denunciando como ilusória a idéia de que as barreiras entre as artes estariam em processo de desmoronamento. Assim como Greenberg, Fried acreditava que "um novo episódio na evolução" da arte norte-americana vinha se dando por meio do trabalho de pintores e escultores que aprenderam com o expressionismo abstrato e que pareciam dispostos a "prolongar a empreitada modernista de autodefinição da arte". Entre seus maiores representantes estavam Morris Louis, Helen Frankenthaler, Jules Olitski, Kenneth Noland e Anthony Caro.

Em seu célebre artigo, "Arte e objetidade", publicado em 1967, Fried discorre sobre a "sensibilidade corrompida ou pervertida pelo teatro" das pro-

\footnotetext{
${ }^{10}$ Clement Greenberg, “A necessidade do formalismo”, in Glória Ferreira e Cecília Cotrim (orgs.), op. cit., pp. 128. Artigo publicado pela primeira vez in New Literary History, vol. III, 1971-72. O grifo é nosso.

${ }^{11}$ Jean-Pierre Criqui, "O modernismo e a Via Láctea (Nota sobre Clement Greenberg), in Glória Ferreira e Cecília Cotrim (orgs.), op. cit., p. 239.
} 
postas minimalistas (ou literalistas, como gostava de escrever), alertando que "a arte entra em degeneração à medida que se aproxima da condição de teatro". Em sua opinião, "a sensibilidade literalista era teatral porque (...) estava interessada nas circunstâncias factuais em que se dá o encontro do observador com o trabalho literalista", preocupando-se com a duração da experiência e visando à criação de uma "especial cumplicidade" entre obra e espectador. Tais características marcavam sua profunda diferença em relação à pintura e à escultura modernistas, as quais almejavam "produzir ou constituir um contínuo e perpétuo presente". "É como se experiência que se tem destas últimas", escreve Fried, "não tivesse duração - não porque de fato não se experimenta uma pintura de Noland ou de Olistki ou uma escultura de David Smith ou de Caro em momento algum, mas porque a todo momento o próprio trabalho se faz totalmente manifesto". Além disso, se para os artistas minimalistas "tudo o que importava era se um determinado trabalho era ou não capaz de invocar ou manter (seu) interesse", para a arte modernista "nada além da convicção (...) de que uma dada pintura ou escultura ou poema ou peça musical pode ou não resistir à comparação com trabalhos do passado de inquestionável qualidade no âmbito daquela arte realmente importa". ${ }^{12}$

O apego de Greenberg e de Fried a uma análise exclusivamente formal, assim como sua recusa em pensar a modernidade em termos de ruptura com o passado ou em valorizar a integração entre arte e vida foram determinantes para que a maioria dos historiadores interessados em analisar a arte contemporânea rejeitassem a teoria modernista. Antigos discípulos ou admiradores de Greenberg, embora jamais tenham negado o papel histórico de sua atuação como critico, acabaram por rebelar-se contra a pretensão universalista e o caráter dogmático da explicação por ele proposta. O que parecia ser um "modelo pragmático de boa crítica de arte", um método "que exigia lucidez" e que era capaz de "explicar os fatos pictóricos mais importantes dos últimos cem anos como uma progressão compreensível” revelou-se, aos olhos de alguns, uma teoria normativa e prescritiva, responsável por uma interpretação que "reduzia a arte dos últimos cem anos a um elegante fluxo unidimensional". ${ }^{13}$ Nesse sentido, o depoimento de Rosalind Krauss é elucidativo.

Segundo Krauss, a grande adesão à teoria greenberguiana, nos Estados Unidos, deu-se sobretudo porque, no início dos anos 1960, a metodologia modernista apresentava-se como uma alternativa efetiva contra "a lamúria psicologizante da crítica existencialista dos anos 1950". "A solução, a nosso ver [dos

\footnotetext{
${ }^{12}$ Michael Fried, “Arte e objetidade”, in Arte \& Ensaios. Revista do Programa de Pós-graduação em Artes Visuais, EBA-UFRJ, Rio de Janeiro, ano IX, número 9, 2002, pp. 131-147.

${ }^{13}$ As citações entre aspas são de autoria de Thierry de Duve, Rosalind Krauss e Leo Steinberg, respectivamente.
} 
modernistas]", relembra Krauss em 1972, "estaria numa demonstração clara do tipo: 'se x, logo y'. O silogismo que adotamos era de origem histórica, o que significava que só podia ser lido numa direção; era progressista”. Entretanto, ressalta Krauss apontando os equívocos de uma visão que se pretende objetiva, acima dos ditames da sensibilidade e da ideologia, "não sendo capaz de ver sua 'história' como uma perspectiva, (...) isto é, um ponto de vista, a crítica modernista deixou de desconfiar do que via (...), tendo sua inteligência crítica perdido a prudência em relação ao que tomou como dado". ${ }^{14}$

Dentro desse mesmo espírito, Leo Steinberg também contestou os pressupostos da teoria modernista e da crítica formalista em seu texto "Outros critérios", publicado no mesmo ano de 1972, afirmando estar "sempre em permanente oposição ao chamado formalismo não porque duvide da necessidade de análise formal, ou do valor positivo do trabalho feito por críticos formalistas sérios. Mas porque desconfio de suas certezas, de seus aparatos de quantificação, de sua indiferença farisaica àquela parcela de expressão artística que suas ferramentas não medem. Desagrada-me acima de tudo a sua postura proibitória - a atitude que consiste em dizer a um artista o que ele não deve fazer, e ao espectador o que ele não deve ver". ${ }^{15}$

Em "A arte contemporânea e a situação do seu público", conferência proferida em 1960, Steinberg relata a sensação de desconforto que lhe trouxe a primeira exposição individual de Jasper Johns, em 1958, com o objetivo de demonstrar que uma arte nova pode por vezes exigir novos critérios de julgamento. "Minha primeira reação foi normal", escreve Steinberg a propósito da exposição. "Não gostei [dela] e com muito prazer eu a classificaria como tédiosa. No entanto, ela me deprimiu sem que eu soubesse explicar por quê. Comecei então a reconhecer em mim mesmo todos os clássicos sintomas dos filisteus à arte moderna. Estava enfurecido com o artista, como se ele houvesse me convidado para comer, unicamente, para servir-se algo intragável como estopa e parafina. Estava irritado com alguns amigos meus por fingirem gostar dele mas com uma incômoda supeita de que talvez estivessem realmente gostando; enfim, estava na verdade descontente comigo mesmo, por ser tão burro, e com a situação, por me expor. Enquanto isso", continua o crítico, "os quadros continuavam dentro de mim - trabalhando-me e deprimindo-me. A sua lembrança dava-me um sentido bem claro de ameaça, de perda ou de destruição. (...) Pois, o que realmente me deprimia era o que pressentia que aquelas obras poderiam fazer a todas as outras formas de arte. Parecia-me subitamente que os quadros

\footnotetext{
${ }^{14}$ Rosalind Krauss, "Uma visão do modernismo", in Glória Ferreira e Cecília Cotrim (orgs.), op. cit., pp. 167 e 169. Artigo publicado originalmente in Artforum, setembro de 1972.

${ }^{15}$ Leo Steinberg, “Outros critérios”, in Glória Ferreira e Cecília Cotrim (orgs.), op. cit., pp. 183.
} 
de De Kooning e de Kline estavam sendo jogados no mesmo caldeirão onde estavam Rembrandt e Giotto. Todos pareciam ter-se tornado repentinamente pintores ilusionistas". Steinberg sentia-se além disso perdido pois qualquer experiência sobre pintura que porventura tivera no passado parecia-lhe mais um estorvo do que um auxílio. "Sou desafiado a calcular o valor estético, digamos, de uma gaveta enfiada na tela. Mas nada de tudo o que já vi pode ensinar-me como fazer isto. Permaneço sozinho com esta coisa e cabe a mim julgá-la, na ausência de padrões convencionais. $O$ valor que atribuir a esta pintura será a medida da minha coragem."16

Para Steinberg, sensação similar de desconforto também fora vivenciada pelos críticos formalistas em relação à arte pop. Entretanto, afirma, eles optaram por rejeitá-la em bloco, sem qualquer consideração de mérito ou valor individual, o que demonstrava que, naquele momento, eles "não puderam sequer enfrentar a questão da qualidade ou relutaram em fazê-lo, temendo que o exercício do juízo estético conferisse indevida dignidade a uma aberração". ${ }^{17}$

Outro crítico que não tardou a celebrar o fim da "ditadura dos expressionistas abstratos" foi Arthur Danto. Em diversos artigos, Danto queixou-se do ambiente repressivo e exclusivista do meio artístico nova-iorquino dos anos 1950, denunciando que "os expressionistas abstratos possuíam as teorias mais duras e dogmáticas sobre o que contava ou não como arte. (...) Naqueles anos, certamente os anos de glória da pintura americana, a atmosfera era puritana e condenadora de hereges". ${ }^{18}$ Embora reconhecesse a qualidade da escrita de Greenberg e afirmasse acreditar que "seus textos (...) permanecerão um monumento e um modelo de pensamento sério sobre arte, história, cultura, beleza e significado", ${ }^{19}$ ele discordava inteiramente de sua leitura da arte dos anos 1960 e do dogmatismo de suas afirmações. $A$ pop art, escreveu Danto, "foi a primeira de uma vasta gama de façanhas artísticas que Greenberg estigmatizou como novidadeirice, o que para ele significava que tal tipo de arte privilegiava choque e modismo em detrimento dos grandes princípios modernistas que ele tanto fizera para articular. Ele não estava interessado em arte baseada em novidades, e considerava isto como uma aberração do modernismo, o qual, a seu ver, continuava a definir a arte mais atual, mesmo se a maioria do que estava sendo pro-

\footnotetext{
${ }^{16}$ Leo Steinberg, “A arte contemporânea e a situação do seu público”, in Gregory Battcock, A nova arte, São Paulo, Perspectiva, 1975, pp. 254-256.

${ }^{17}$ Leo Steinberg, "Outros critérios", op. cit., p. 186.

${ }_{18}$ Arthur C. Danto, "Learning to Live with Pluralism”, in Gregg Horowitz e Tom Huhn (orgs.), Arthur C. Danto. Essays. The Wake of Art: Criticism, Philosophy and the Ends of Taste, Amsterdam, G + B Arts International, 1998 , p. 87.

${ }_{19}$ Arthur C. Danto, "Clement Greenberg", The Madonna of the Future. Essays in a Pluralistic Art World, Berkeley, University of California Press, 2000, 66-67.
} 
duzido era novidadeirice e não se encaixava de modo algum nos cânones críticos do modernismo". 20

Contrariando a análise greenberguiana, Danto pregava que movimentos como a pop art e o minimalismo propiciaram o fim da concepção modernista de arte e o início de uma nova era, de uma nova "mentalidade", marcada por uma visão pluralista da produção e do debate artísticos. Para Danto, o fato de a nova "vanguarda" dos anos 1960 interessar-se por questões que eram inteiramente alheias ao credo modernista não significava que ela fosse de menor relevância ou que anunciasse um período de decadência no mundo das artes. Qualquer análise não comprometida dos novos movimentos deveria considerar sua dimensão negativa e ponderar o fato de todos eles terem se estruturado como uma reação às "altas" pretensões do expressionismo abstrato e às suas certezas a respeito dos padrões de boa arte.

$\mathrm{Na}$ realidade, muito da incompreensão generalizada em relação à arte contemporânea em seus primórdios decorria, em sua opinião, da insistente utilização de parâmetros de análise modernistas, sendo que os artistas da nova geração rechaçavam os ideais estéticos do passado mais recente. Por meio de seus trabalhos, eles procuravam demonstrar a estreiteza da estética expressionistaabstrata e dos critérios formalistas de avaliação, colocando em questão a real abrangência - e o real valor - de suas asserções. Como então adotar os mesmos critérios para analisar obras como Vir Heroicus Sublimus, de Barnett Newman, e Female Underpants, de Robert Watt, pergunta-se Danto, sem exaltar um trabalho e vilipendiar o outro? A seu ver, os artistas pop, assim como os minimalistas, haviam demonstrado, por caminhos diferentes, que não se podia predeterminar como uma obra de arte deveria ser e que tampouco existia uma forma mais adequada do que outra de se fazer arte.

Mais recentemente, em publicação vinculada à elaboração de uma grande exposição, L'informe: mode d'emploi, Rosalind Krauss e Yve-Alain Bois questionaram o caráter ontológico da interpretação greenberguiana, propondo-se a derrubar alguns de seus mitos fundadores. ${ }^{21}$ Assinalando que desde que a arte e em especial a pintura - libertou-se da opressão da representação, ela precisou justificar sua existência como uma busca da própria essência, Krauss e Bois denunciaram que a teoria modernista alicerçava-se em um certo número de postulados e de exclusões: 1 . o postulado de que a pintura dirige-se essencialmente à visão e que, sendo puramente visual, dirige-se ao homem como criatura ereta, o que renegaria o eixo horizontal que rege a vida animal; 2. o postulado de que a pintura oferece-se por completo, e em um só instante, ao olho do

\footnotetext{
${ }^{20}$ Arthur C. Danto, “Hand Painted Pop”, Idem, p. 18.

${ }^{21}$ Yve-Alain Bois e Rosalind Krauss, L'informe: mode d'emploi, Paris, Centre Georges Pompidou, 1996.
} 
espectador implica a exclusão da temporalidade, tanto da experiência visual quanto do corpo do observador, e separa o visível do carnal; 3. o postulado de que a arte é uma atividade sublimatória, que congrega o espectador, relaciona a experiência estética a uma plenitude formal e impõe como parâmetro de julgamento do talento de um artista sua capacidade de pensar a tela como uma unidade.

Entretanto, alguns artistas modernos já haviam colocado em xeque a validade de tais postulados. Duchamp, acreditavam, foi o primeiro a denunciar o recalque do corpo na arte modernista, fazendo irromper a pulsação do libidinal no campo visual. "Esse artista que denunciava a pintura pelo que ela tinha de retiniano, revelou, com efeito, que ela só é retininana se ignorarmos o que, no funcionamento retiniano, apela diretamente ao corpo. Operando um curtocircuito, ele conectou o "puramente ótico" ao libidinal".22 Jackson Pollock, por outro lado, foi talvez o primeiro a enfatizar a horizontalidade do suporte como elemento essencial de seu processo de trabalho. "Ao abandonar o pincel e renunciar à ligação anatômica que fazia do instrumento do pintor a prolongação de sua mão, Pollock delegou uma parte de seus poderes de criador à própria matéria". ${ }^{23}$ Essa ruptura radical foi ignorada, na época, tanto por Greenberg quanto por Rosenberg, que privilegiava a experiência em detrimento do resultado em suas análises de teor existencialista, mas foi rapidamente percebida por artistas com Rauschenberg, Morris e Warhol.

Buscando modificar a grade de leitura que por muito tempo orientou nossa aproximação do moderno, Krauss e Bois propuseram, em seu texto, uma classificação porosa, uma taxinomia volátil, para as diferentes manifestações artísticas do século XX, cujo maior interesse seria o de romper com as unidades mais amplas que regem a história da arte, a saber: o tema, o estilo, a cronologia e a obra como um corpus de produção de um artista. Nesse sentido, algumas obras até então consideradas menores de figuras-chaves da arte moderna, como Picasso, seriam revalorizadas, assim como alguns artistas marginalizados pelo grande discurso modernista seriam resgatados do esquecimento.

"Trata-se, para nós", afirmam os autores, "de redistribuir as cartas do modernismo (...) de fazer de forma que a unidade do modernismo, constituída pela oposição entre formalismo e iconologia, seja atacada como um todo, e que algumas obras não possam mais ser lidas como antes". ${ }^{24}$ Para tanto, elegeram o informe, tal como definido por Georges Bataille, como categoria operatória de leitura do moderno, tomando à contra-corrente a interpretação proposta por

\footnotetext{
22 Idem, p. 31.

${ }^{23}$ Ibidem, p. 27.

24 Idem, p. 15.
} 
Greenberg. Interessava-lhes analisar o duplo uso das coisas: o uso elevado, consagrado pelo idealismo metafísico, e o uso baixo, rasteiro, utilizado por Bataille nos textos que publicou na revista Documents. Interessava-lhes romper com a oposição dialética entre modernismo e kitsch e rever a idéia greenberguiana da vanguarda como "um anjo vindo liberar a cultura de sua tentação kitsch", demonstrando que, desde sua origem, o kistch jamais foi completamente estranho à arte moderna. Nesse sentido, não hesitaram em apontar o aspecto kitsch das telas rasgadas de fundo dourado ou de cores pastéis, de pedras e miçangas coladas, de autoria de Lúcio Fontana, ou afirmar que a maioria das obras de Fautrier deve seu tom patético muito mais a sua artificialidade do que a seu expressionismo declarado e que uma tela de Pollock, como Full Fathom Five, pode ser lida como um ovo estrelado.

Maria de Fátima Morethy Couto. A autora é mestre em História da Arte e da Cultura pela Unicamp e doutora em História da Arte pela Universidade de Paris I - Panthéon/Sorbonne. Obteve bolsa de pósdoutorado da FAPESP de 1999 a 2002 para desenvolver pesquisa sobre a crítica de vanguarda no Brasil e nos Estados Unidos durante as décadas de 1950 e 1960. Parte dessa pesquisa foi publicada recentemente pela Editora da Unicamp (Por uma vanguarda nacional. A crítica brasileira em busca de uma identidade artística). É co-autora do livro ABCdaire Cézanne, publicado em 1995, em Paris, pela editora Flammarion. Escreveu diversos artigos dedicados à arte brasileira do século XX e à crítica de vanguarda do Brasil e do exterior. É professora de História da Arte do Departamento de Artes Plásticas do Instituto de Artes da Unicamp. 